\title{
Correspondence
}

\section{Pyridoxine responsive epilepsy: expanded pyridoxine dependency?}

Sir,

Bankier et al. suggest ${ }^{1}$ that the syndrome of autosomal recessive pyridoxine dependency should be expanded and that all infants with refractory epileptic seizures must be given an adequate trial of pyridoxine. On the other hand, there are many case reports of infantile spasms of diverse aetiology (Down's syndrome, ${ }^{2}$ haemophilia $\mathrm{A},{ }^{3}$ etc) that have stopped after pyridoxine. After a dramatic response it may be difficult to withdraw and reintroduce pyridoxine to confirm its specific therapeutic effect. ${ }^{4} \mathrm{We}$ present a case of childhood epilepsy, which is unequivocally pyridoxine responsive but highly atypical, to open the general question of what is the basis of this responsiveness.

A girl, now aged 3 years, had twitching episodes at age 6 days and was given phenobarbitone and antibiotics for five days. At 5 months she had one brief rigid-shaking convulsion with fever. From $7 \frac{1}{2}$ months she had escalating, frequent refractory seizures commonly right or left hemiclonic, long bouts of left upper limb tremor without EEG change, generalised clonic seizures and two episodes of clonic status epilepticus finally controlled by chlormethiazole. Interictal EEG's contained slow or ragged generalised spike wave. Phenobarbitone, carbamazepine, clonazepam, valproate, phenytoin, and phenytoin plus phenobarbitone were ineffective. After 3 months almost constantly spent in hospital she was given pyridoxine (100 mg a day). Seizures stopped after the first dose, but she was also on phenobarbitone $60 \mathrm{mg}$ and clonazepam $0.5 \mathrm{mg}$ (!). After two months without fits, pyridoxine was stopped and three days later she had a flurry of seizures. Pyridoxine was started, but after two or more months free of fits it was again stopped. Hemiclonic and generalised seizures recurred after three days. During a generalised clonic seizure $50 \mathrm{mg}$ of intravenous pyridoxine stopped limb twitching in three minutes but facial twitching continued and diazepam was given. Oral pyridoxine was restarted for the third time and clonazepam tailed off. Phenobarbitone was withdrawn once her mother had successfully concluded her next pregnancy. After a stable interval on pyridoxine alone, this was stopped in hospital with continuous ambulatory EEG monitoring at the age of 2 years. Four days later seizures increased over a few hours with generalised high voltage spike and waveform. Intravenous pyridoxine was restarted for the fourth and last time and will be continued indefinitely. No seizures have been observed since, and at follow up, despite having had no therapeutic pyridoxine in infancy, she is developmentally normal, with a normal EEG.

There is a recent report ${ }^{4}$ of 'pyridoxine dependency' in a child with minor motor seizures from 14 months, and
Dr Sydney Gellis ${ }^{5}$ has referred to an unpublished case of a 3 year old with mixed seizure disorder that responded to pyridoxine. Even more so than in our patient, it is stretching classical pyridoxine dependency too far to force the inclusion of these two. The need may not be so much for recognition of the wider clinical spectrum of this condition but rather for a rethinking of the meaning of pyridoxine dependency. How does it differ from dependency on one of the classic antiepileptic drugs in mechanism and ontogeny? Well done to the Melbourne group for stimulating renewed interest in this.

\section{References}

1 Bankier A, Turner M, Hopkins IJ. Pyridoxine dependent seizures-a wider clinical spectrum. Arch Dis Child $1983 ; 58: 415-8$

2 Wolcott GJ, Chun RWM. Myoslonic seizures in Down`s syndrome. Dev Med Child Neurol 1973;15:805-8.

3 Tajima T, et al. The effect of Vitamin B6 in a boy with infantile spasms. (abstract). Brain Dev 1983,5:62.

4 Krishnamoorthy KS. Pyridoxine-dependency seizure report of a rare presentation. Ann Neurol 1983;13:103-4

Gellis S. Pediatric Notes 1983;7:101.

J B P STEPHENSON Fraser of Allander Unit and EEG Department, Royal Hospital for Sick Children, Yorkhill, Glasgow G3 8SJ

K E ByRne, Hawkhead Hospital, Hawkhead Road, Paisley PA2 7BL

\section{Prelaparotomy diagnosis of extrahepatic biliary atresia}

Sir,

We are surprised that in their search for a simple noninvasive test to differentiate between extrahepatic biliary atresia and other causes of conjugated hyperbilirubinaemia', Manolaki et al. ${ }^{1}$ do not discuss the use of ultrasonography. A report from Gates et al..$^{2}$ evaluated 33 children with cholestasis with grayscale sonography and ${ }^{131}$ I rose bengal scintigraphy. They found that 17 of 19 children with extrahepatic cholestasis had abnormal sonograms; five had choledochal cysts, 9 had acquired biliary obstruction, while three of five patients with isolated extrahepatic biliary atresia had dilated intrahepatic ducts. All 14 patients with intrahepatic cholestasis had normal sonograms. ${ }^{131}$ I rose bengal excretion was abnormal in all cases of extrahepatic biliary atresia 
and in 7 of 9 patients with intrahepatic cholestasis, proving a poor discriminatory test.

As ultrasound is safe, non-invasive, and does not depend on hepatobiliary function we routinely use it to screen all cholestatic patients before proceeding to liver biopsy or laparotomy as required.

P ShaW AND D A Kelly Departments of Paediatrics and Medicine, Royal Free Hospital, Pond Street, London NW3

Drs Mowat Hylton, and Meire comment:

All infants with conjugated hyperbilirubinaemia admitted to our unit have ultrasound examination before liver biopsy. If dilated extrahepatic ducts are found, laparotomy for presumed choledochal cyst is considered without prior liver biopsy. We would see little prospect of ultrasonography of the extrahepatic biliary tree helping in the differentiation between extrahepatic biliary atresia and infants with severe intrahepatic cholestasis with reduced bile flow. Even with operative cholangiography at laparotomy, experienced surgeons may make a presumptive diagnosis of atresia in patients with patent bile ducts, and proceed to unnecessary surgery with deleterious results. ${ }^{3}$

The intrahepatic bile ducts in extrahepatic biliary atresia are commonly very narrow. We have not observed dilated intrahepatic ducts on ultrasound in over 60 infants with extrahepatic biliary atresia, aged less than 20 weeks, examined in the last three years. When ultrasonography of the hepatic parenchyma has been compared with histological observations, marked discrepancies have emerged. ${ }^{4}$

Our summary concluded 'In patients in whom genetic disorders, such as alpha-l antitrypsin deficiency had been excluded, interpretation of liver biopsy specimens, together with ${ }^{131}$ I rose bengal faecal excretion, remains the most accurate means of identifying those infants who need surgery for biliary atresia and of avoiding unnecessary laparotomy in infants with intrahepatic disease'. Our experience since completing this work reinforces this conclusion but the word 'interpretation' should have been qualified by 'skilled'.

\section{References}

1 Manolaki AG, Larcher VF, Mowat AP, Barrett JJ, Portmann B, Howard ER. The prelaparotomy diagnosis of extrahepatic biliary atresia. Arch Dis Child 1983;58: 591-4.

2 Gates GF, Sinatra FR, Thomas DW. Cholestatic syndromes in infancy and childhood. American Journal of Radiology 1980;134:1141-8.

3 Markowitz J, Daum F, Kahn EI, et al. Arterio-hepatic dysplasia. Pitfalls in diagnosis and management. Hepatology 1983;3:74-6.

4 Gosink BB, Lemon SK, Scheible W, Leopold GR. Accuracy of ultrasonography in the diagnosis of hepatocellular disease. $A J R$ 1979; 133:19-26.

\section{Changing incidence of infantile hypertrophic pyloric stenosis}

Sir,

The papers from Birmingham ${ }^{1}$ and from South Wales ${ }^{2}$ show an increased incidence of pyloric stenosis. The authors have various suggestions for this increase; but is it anything more than better diagnosis? In most paediatric units the decision to operate is made on the basis of a convincing history and the finding of a palpable pyloric mass. Over the years I have been amazed that, even at times when I have been a little doubtful about the presence of such a pyloric mass, surgeons at operation have always found hypertrophic pyloric stenosis and performed a Ramstedt's operation. This must mean that, in general, I and perhaps other paediatricians are underdiagnosing pyloric stenosis, because I cannot believe that for any condition I am $100 \%$ correct.

In the last 10 years there has been a great increase in both the number and the expertise of paediatric staff in all British paediatric units, both peripheral and central. Might not the increased incidence of pyloric stenosis be the result of fewer such babies being missed (after all, the natural history for the less severe case is for spontaneous resolution to occur with time). If this is not the explanation, can the authors explain how, in contrast to the rest of my life, I have never been wrong in diagnosing pyloric stenosis?

\section{S R Meadow St James's University Hospital, Beckett Street, Leeds LS9 $7 T$ F}

\section{Drs Webb, Dodge, and Lari comment:}

Professor Meadow's clinical expertise has never been in doubt, but we hasten to assure him that not all paediatricians are quite as good as he at detecting pyloric stenosis. He may well be right that pyloric stenosis is underdiagnosed, and there is some evidence that silent cases do occur. ${ }^{8}$ However, although there has been an increase in the number of paediatric staff throughout the country, their expertise in palpation of pyloric tumours is probably no better than that of their predecessors, and we have personally encountered senior registrars who have never felt a pyloric tumour.

Before the abrupt rise in incidence which we and others have reported, most paediatricians were under the impression that it was a declining problem and the few epidemiological studies reported would seem to support this contention. ${ }^{45}$ There is no evidence from our own records that the recent excess of babies with pyloric stenosis are of a milder clinical nature, who would formerly have been missed, nor has the increase in paediatric manpower been abrupt, at least in this part of the world. One of us (JAD) spent several years actively looking for cases all over Belfast, and can assure Professor Meadow that 'any infant who vomited' was regarded as a potential candidate. In spite of this enthusiasm, the recorded incidence of hypertrophic 